\title{
Proof of concept: a spatial modular small-world self-organises by adaptive rewiring
}

\author{
Nick Jarman ${ }^{1,2^{*}}$, Chris Trengove ${ }^{1}$, Erik Steur ${ }^{1}$, Ivan Tyukin ${ }^{2,3}$, Cees van Leeuwen ${ }^{2}$ \\ From 24th Annual Computational Neuroscience Meeting: CNS*2015 \\ Prague, Czech Republic. 18-23 July 2015
}

A small-world network is a network that reconciles two opposing properties, segregation and integration. It is this reconciliation that gives rise to the impressive information processing capacity of the human brain; segregation provides a platform for information processing, whilst integration provides for the fast transmission of information. However, the connectivity structure of the brain is not static [1]; it changes on multiple time-scales; on a relatively fast time-scale, synaptic plasticity takes place, whilst on a slower time-scale there is rewiring of brain connectivity through growth of axons and dendrites. This structural plasticity depends on the even faster time-scale of neural activity. But the relationship is symbiotic: patterns of synchronous activity are, of necessity, mediated by the brain connectivity structure. Gong \& van Leeuwen [2] showed that rewiring of an initially random network - adaptive rewiring - in a model of spontaneous cortical activity gives rise to a particular type of network connectivity structure: a modular smallworld. In order to improve the applicability of such a model to the cortex, spatial characteristics of cortical connectivity need to be respected. For this purpose we consider networks endowed with a metric by embedding them into a physical space. Such spatial constraints may represent wiring and metabolic costs in the brain. We provide an adaptive rewiring model with a spatial

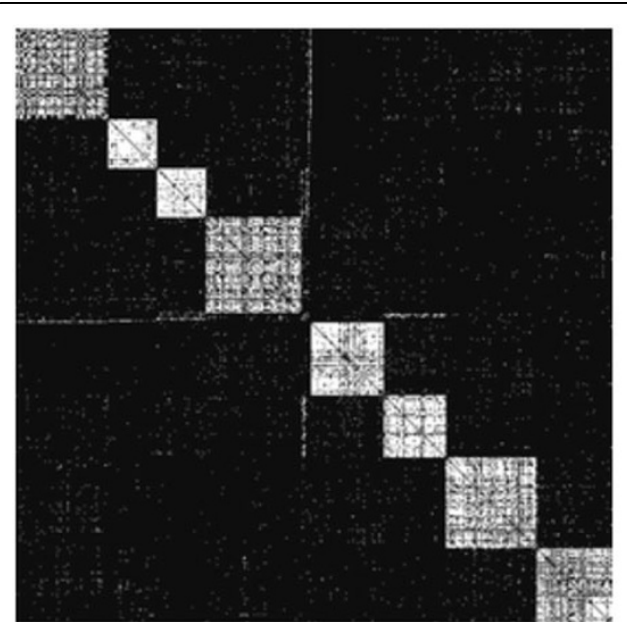

A

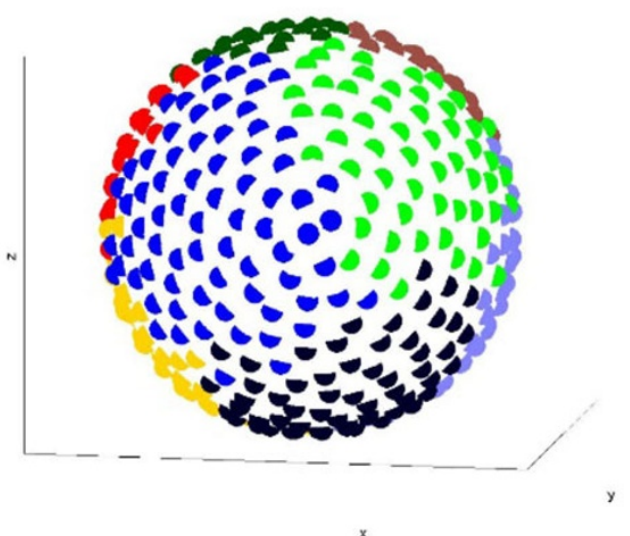

B

Figure $1 \mathrm{~A}$, Network adjacency matrix organised to optimise visual presentation of modular structure. B, Units on the sphere colourcoded to identify distinct modules.

\footnotetext{
* Correspondence: nick.jarman@ppw.kuleuven.be

${ }^{1}$ Perceptual Dynamics Laboratory, University of Leuven, Leuven, Flemish

Brabant, B3000, Belgium

Full list of author information is available at the end of the article
} 
distance function and a corresponding spatially local rewiring bias [3].

\section{Conclusion}

The resulting rewiring scenarios showed a spatial layout of the connectivity structure, in which topologically segregated modules correspond to spatially segregated regions, and these regions are linked by long-range connections (see Figure 1, A and B). Greater realism and increased efficiency and robustness of the symbiosis of activity and structure is achieved compared to non-spatial adaptive rewiring. Thus, the principle of locally biased adaptive rewiring may explain both the topological connectivity structure and spatial distribution of connections between neuronal units in a large-scale cortical architecture.

\section{Authors' details}

${ }^{1}$ Perceptual Dynamics Laboratory, University of Leuven, Leuven, Flemish Brabant, B3000, Belgium. ²Department of Mathematics, University of Leicester, Leicester LE1 7RH, UK. ${ }^{3}$ Saint-Petersburg State Electrotechnical University, Saint-Petersburg, Saint Petersburg 197376, Russia.

Published: 18 December 2015

\section{References}

1. Zhang LI, Poo MM: Electrical activity and development of neural circuits. Nat Neurosci 2001, 4:1207-1214

2. Gong P, van Leeuwen C: Evolution to a small-world network with chaotic units. Europhys Lett 2004, 67:328-333.

3. Jarman N, Trengove C, Steur E, Tyukin I, v. Leeuwen C: Spatially constrained adaptive rewiring in cortical networks creates spatially modular small world architectures. Cognitive Neurodynamics 2014, 8:479-497.

doi:10.1186/1471-2202-16-S1-P272

Cite this article as: Jarman et al: Proof of concept: a spatial modular small-world self-organises by adaptive rewiring. BMC Neuroscience 2015 16(Suppl 1):P272.

\section{Submit your next manuscript to BioMed Central} and take full advantage of:

- Convenient online submission

- Thorough peer review

- No space constraints or color figure charges

- Immediate publication on acceptance

- Inclusion in PubMed, CAS, Scopus and Google Scholar

- Research which is freely available for redistribution

Submit your manuscript at www.biomedcentral.com/submit 